\title{
AUDIT
}

\section{An audit of activity and outcome from a daily and a weekly "one stop" rapid assessment chest pain clinic}

\author{
J Byrne, D Murdoch, C Morrison, J McMurray
}

Postgrad Med J 2002;78:43-46

See end of article for authors' affiliations

Correspondence to: Dr John Byrne, Department of Cardiology, Southern General Hospital,

Govan Road, Glasgow

G53 4TF, UK;

John.Byrne@sgh.scot.nhs.uk

Submitted

5 February 2001

Accepted 2 July 2001

\begin{abstract}
Objectives: The recent National Service Framework for coronary heart disease advocates the establishment of rapid assessment clinics for chest pain. But how should these clinics be organised and do they fulfil their objectives? The aim of this study was to compare referral patterns to a daily and a weekly "one stop" rapid access chest pain clinic (RACPC), and to examine clinical outcome in patients attending these clinics.

Design: Patients were prospectively categorised into one of the following subgroups: "acute coronary syndrome", "stable coronary heart disease", or "low risk/non-coronary chest pain". Fatal and non-fatal outcomes were audited over eight months.

Setting: Both RACPCs were situated within the cardiology departments of two large Glasgow teaching hospitals. Patients were seen by a cardiologist, and underwent non-invasive testing.

Participants: A total of 633 patients with chest pain who were referred by their general practitioner; 500 came to the daily and 133 to the weekly clinic. Forty four $(7 \%)$ were categorised as having an acute coronary syndrome, $267(42 \%)$ as stable coronary artery disease, and $322(51 \%)$ as low risk/ non-coronary chest pain.

Results: Referral patterns to the two clinics differed significantly. Compared with the weekly clinic, more patients with an acute coronary syndrome $(7.8 \vee 3.8 \%)$ and low risk/non-coronary chest pain $(55.2 \vee 35.6 \%)$, but fewer patients with stable coronary disease $(37.0 \vee 61.6 \%)$ were referred to the daily clinic $(p<0.00001)$.

During follow up eight (1.3\%) patients died from a cardiac cause, and eight (1.3\%) patients suffered a myocardial infarction. None of these patients were classified as low risk/non-coronary chest pain. Conclusions: (1) RACPCs do provide an effective tool for the early assessment of patients with possible angina. (2) The frequency with which clinics are scheduled may be an important factor in determining how the service is utilised in practice.
\end{abstract}

$\mathrm{T}$ here are major shortcomings in the existing system for the management of patients developing chest pain. At present, only a minority are referred by their general practitioners for a specialist opinion, ${ }^{1}$ despite the difficulties with making the correct diagnosis, and the serious consequences of not recognising an acute coronary syndrome.

However, even if patients are referred-on, there may still be problems. For example, patients referred electively through the conventional outpatient system can wait several weeks or even months before they are seen. This delay may be crucial, since more than $10 \%$ of patients will die or suffer myocardial infarction within a year of developing angina. ${ }^{2}$ On the other hand, patients referred directly to accident and emergency departments as emergencies may also receive suboptimal care, not least because they are often assessed by the most junior, and hard pressed, doctors. Some presenting with an acute coronary syndrome may be designated "low risk" or "non-cardiac" and discharged inappropriately, on the basis of having a normal resting electrocardiogram. ${ }^{3}$ Still others who are genuinely low risk may be admitted to hospital unnecessarily.

Many of these shortcomings have been highlighted in the government's National Service Framework (NSF) covering England. ${ }^{6}$ This initiative is designed to improve the management of a range of common cardiovascular conditions, including angina. The recommendations contained therein are likely to cause a significant increase in referrals from primary care. At the same time, however, the NSF requires that the waiting time from referral to specialist consultation is to be reduced, ultimately to two weeks for a patient with new onset angina. Clearly these conflicting targets will not be met without substantial restructuring of current services.
Rapid access chest pain clinics (RACPCs) might provide one solution to some of these problems. Indeed, one of the key proposals of the NSF is the early expansion of such services. One hundred clinics are envisaged by April 2002, with more to follow thereafter. This proliferation is set to occur despite the fact that the impact of RACPCs on overall patient care has not yet been properly established. It is not even clear how the service should best be structured to achieve its aims.

We have carried out an audit of two RACPCs in Glasgow, one of which runs every weekday, while the other runs once a week. We had two main objectives. Firstly we wished to obtain some insights into how the provision of the service affects utilisation. We have compared the clinical characteristics of patients referred to the two clinics, and discuss the implications for developing rapid access services in future. Secondly, we wanted to ensure that patients were stratified and managed appropriately. To date long term follow up of substantial numbers of patients seen in these clinics has not been available.

\section{METHODS}

Location and organisation of chest pain clinics

This study is based on an audit of RACPCs in two neighbouring teaching hospitals in Glasgow. Both centres have cardiology departments providing a comprehensive range of invasive

Abbreviations: NSF, National Service Framework; RACPCs, rapid access chest pain clinics 


\begin{tabular}{llll} 
Table 1 & Characteristics of patients referred to the RACPC & \\
\hline & $\begin{array}{l}\text { Western Infirmary } \\
(n=500)\end{array}$ & $\begin{array}{l}\text { Southern General } \\
\text { Hospital }(n=133)\end{array}$ & $\begin{array}{l}\text { All patients } \\
(n=633)\end{array}$ \\
\hline $\begin{array}{l}\text { Mean (SD) age (years) } \\
\text { Characteristic (\%) }\end{array}$ & 59.7 & 59.1 & $59.5(11.8)$ \\
Male & 53.2 & 60.9 & 54.9 \\
Previous MI & 9.0 & 6.0 & 8.4 \\
Hypertension & 28.6 & 31.6 & 29.2 \\
Diabetes (any) & 4.6 & 5.3 & 4.7 \\
PTCA & 1.2 & 1.5 & 1.3 \\
CABG & 5.2 & 3.0 & 4.7 \\
Category (\%)** & 7.8 & 3.8 & 7.0 \\
Acute coronary syndrome & 37.0 & 61.6 & 42.2 \\
Stable coronary disease & 55.2 & 34.6 & 50.9 \\
Low risk/non-coronary & & &
\end{tabular}

and non-invasive investigations, and since 1996 both have offered RACPCs as part of their clinical service. The main aim of both these clinics was to expedite the assessment of patients with recent onset chest pain. It was hoped that a further consequence might be to reduce unnecessary hospitalisation of patients with little likelihood of cardiac disease.

One centre (Western Infirmary) provides a daily chest pain clinic except at weekends, and generally assesses patients within 24 hours of referral. The other (Southern General Hospital) provides a weekly chest pain clinic and aims to evaluate patients within seven days of referral. Two staff grade cardiologists (supervised by a named consultant) run the Western Infirmary clinic, and a consultant cardiologist runs the Southern General Hospital clinic.

General practitioners in both areas were sent the same guidelines on the types of patients appropriate to this new service. They were specifically advised to refer patients for immediate hospitalisation if they considered acute myocardial infarction to be the likely diagnosis.

\section{Patient assessment}

The format of both clinics was similar. General practitioners were encouraged to refer patients by fax or by telephone to their local clinic, where they were appointed directly. An abbreviated clinical assessment was performed, a 12 lead electrocardiogram recorded, and (usually) a treadmill exercise test carried out. Finally, an overall assessment was made based on the clinical findings and the results of these initial investigations, and a computer generated report faxed or posted to the general practitioner. This allowed treatment to be started with

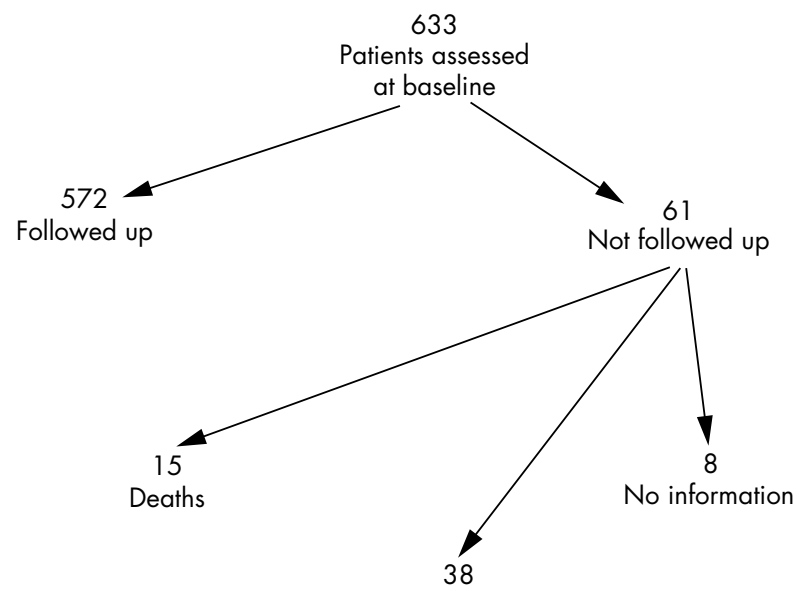

Unwilling, unwell, did not attend, but vital status established

Figure 1 Follow up of patients attending the chest pain clinics. the minimum of delay, and other investigations such as angiography scheduled if indicated.

\section{Patient classification and audit of outcomes}

Two research nurses supervised by JMcM, DM, and CM carried out the audit of the two clinics. For the purposes of audit patients were prospectively classified into one of three groups: (1) "low risk/non-coronary chest pain" (patients felt to have atypical symptoms, a small probability of coronary heart disease and "low risk" test results), (2) "stable coronary artery disease" (patients thought to have coronary heart disease but felt to be clinically stable and not at high risk of early adverse outcome), and (3) "acute coronary syndromes" (patients in whom immediate hospitalisation was advised). The latter group included patients with crescendo angina, angina at rest, or suspected acute myocardial infarct.

\section{Patient follow up}

All patients were invited to a follow up visit 6-12 (median 8) months after their initial attendance when a detailed history of cardiovascular and non-cardiovascular events and modifiable risk factors was recorded. Mortality data were sought from primary care.

\section{Statistical analysis}

Normally distributed data are presented as means (SD), and other data as medians. Comparisons of categorical variables used the $\chi^{2}$ test, or Fisher's exact test for $2 \times 2$ tests when the expected number of variables in any category was less than five. Comparisons of normally distributed variables uses one way analysis of variance and Student's $t$ test (two sided p values quoted). Statistical analysis was carried out using SPSS 8.0.

\section{RESULTS}

Patients referred

A total of 633 consecutive patients were studied of whom 500 attended the daily (Western Infirmary) and 133 the weekly clinic (Southern General Hospital). The baseline characteristics of these patients are shown in table 1 . We have no data on patients who may have been referred to the chest pain services, but failed to attend.

\section{Patient categorisation: differences between clinics}

Forty four patients $(7.0 \%)$ were thought to have an acute coronary syndrome, 267 (42\%) stable coronary heart disease, and $322(51 \%)$ low risk/non-coronary chest pain. These proportions, differed significantly between the two clinics (table 1), with more acute coronary and low risk/non-coronary chest pain patients referred to the daily clinic. 
Table 2 Causes of death in patients attending a RACPC

\begin{tabular}{|c|c|c|c|c|}
\hline Category & Age & Sex & Classification of death & Details of death \\
\hline Acute & 62 & M & Cardiac & $\mathrm{Ml} /$ cardiac arrest (advised urgent admission, but declined) \\
\hline Acute & 67 & $\mathrm{~F}$ & Cardiac & $\mathrm{MI}$, died after $\mathrm{CABG}$ \\
\hline Stable & 67 & $\mathrm{~F}$ & Cardiac & MI, no other details \\
\hline Stable & 60 & $\mathrm{~F}$ & Non-cardiac (other) & Carcinoma bronchus \\
\hline Stable & 79 & $\mathrm{~F}$ & Cardiac & Heart failure \\
\hline Stable & 70 & M & Unknown & Unknown \\
\hline Stable & 81 & $\mathrm{~F}$ & Non-cardiac (cardiovascular) & CVA \\
\hline Stable & 80 & M & Cardiac & MI (post-lobectomy for carcinoma bronchus) \\
\hline Stable & 74 & M & Cardiac & MI, died after $C A B G$ \\
\hline Stable & 72 & M & Cardiac & Waiting list for $C A B G$ \\
\hline Stable & 64 & M & Cardiac & Waiting list for angiography \\
\hline Stable & 61 & $\mathrm{~F}$ & Non-cardiac (cardiovascular) & PTE \\
\hline Non-coronary & 62 & M & Non-cardiac (other) & Hepatic metastases (? primary) \\
\hline Non-coronary & 53 & M & Non-cardiac (other) & Carcinoma oesophagus \\
\hline Non-coronary & 84 & $\mathrm{~F}$ & Non-cardiac (other) & Metastatic carcinoma breast \\
\hline
\end{tabular}

\section{Completeness of follow up}

Altogether 572 patients ( $92.6 \%$ of survivors) were followed up for 6-9 months (median 8 months) after their initial assessment, either in person or by telephone (fig 1). Reasons for non-attendance are shown in fig 1 . There were no significant differences in baseline characteristics between those who did and did not attend for follow up. The vital status of all but eight patients (1.3\%) was ascertained.

\section{Patient outcome}

Overall, there were 15 deaths during follow up, of which eight were cardiac. Details are given in table 2. Total and cardiac mortality was highest in the acute coronary group, intermediate in the stable coronary patients, and lowest in the non-coronary/low risk chest pain group. A similar pattern emerged in terms of non-fatal cardiovascular event rates. The differences were highly significant. Importantly no acute myocardial infarctions or cardiovascular deaths occurred in the non-coronary group, although one patient underwent angioplasty (table 3).

\section{DISCUSSION}

The two key objectives of this study were firstly to compare the pattern of referrals to different types of RACPCs, and secondly to determine the outcome of patients seen in these clinics.

\section{Comparison of patients referred}

The referral pattern to the daily and weekly clinics differed significantly. As might be expected, a higher proportion of patients classified as having an acute coronary syndrome were seen at the daily clinic. This immediately raises several questions. What is the precise function of a RACPC? Should overtly unstable patients to be sent to such clinics? Might these patients be referred to our daily clinic at the expense of a delay of up to 24 hours in their assessment?

\section{High risk patients}

The most important group in this respect is patients with confirmed myocardial infarctions. Most of their associated mortality occurs before hospitalisation due to early ventricular fibrillation. ${ }^{7}$ Immediate defibrillation is potentially lifesaving in this situation. The benefits of thrombolysis are also strongly time dependent. It would be a cause for concern if general practitioners inadvertently deferred admission of patients having a myocardial infarction, and opted instead for referral to a RACPC. In our cohort, 44 patients required immediate admission from the clinic. Eleven proved to be having a myocardial infarction, but none fulfilled our criteria for the use of thrombolytic treatment.

The corollary to this is that early recognition and appropriate treatment of the acute manifestations of coronary artery disease (for example, new onset angina) is also highly desirable and may prevent the fatal and non-fatal events that can occur in the short term in these patients. Newby et al reported that $9 \%$ of patients who presenting to their RACPC with an acute coronary syndrome would have been managed in the community by their general practitioner had the clinic not been available. ${ }^{8}$

\begin{tabular}{|c|c|c|c|c|c|}
\hline & $\begin{array}{l}\text { Acute coronary } \\
\text { syndrome }(n=44)\end{array}$ & $\begin{array}{l}\text { Stable coronary } \\
\text { disease }(n=267)\end{array}$ & $\begin{array}{l}\text { Low risk or } \\
\text { non-coronary } \\
(n=322)\end{array}$ & $\chi^{2}$ & $\mathrm{p}$ Value \\
\hline \multicolumn{6}{|l|}{ Fatal events } \\
\hline Cardiac deaths & $2(4.5)$ & $6(2.2)$ & 0 & 10.0 & 0.007 \\
\hline Non-cardiac deaths & 0 & $4(1.5)$ & $3(0.9)$ & 1.0 & 0.620 \\
\hline Total deaths & $2(4.5)$ & $10(3.7)$ & $3(0.9)$ & 5.96 & 0.051 \\
\hline \multicolumn{6}{|l|}{ Non-fatal events } \\
\hline Chest pain admissions & $15(36.6)$ & $21(8.7)$ & $7(2.4)$ & 62.7 & $<0.00001$ \\
\hline MI & $4(9.8)$ & $4(1.6)$ & & 25.8 & $<0.00001$ \\
\hline Angiography & $23(56.1)$ & $86(33.3)$ & $7(2.4)$ & 119.7 & $<0.00001$ \\
\hline PTCA & $4(9.8)$ & $14(5.8)$ & $1(0.3)$ & 19.6 & $<0.001$ \\
\hline CABG & $8(19.5)$ & $10(4.1)$ & 0 & 48.0 & $<0.00001$ \\
\hline Total (572) & 41 & 242 & 288 & & \\
\hline
\end{tabular}




\section{Low risk patients}

At the other end of the spectrum, many patients deemed to be at low risk or to have non-coronary chest pain were referred to the daily clinic. This might be a potential drawback of easy and rapid assess to such a clinic, since it may lower the threshold for referral excessively. It is, however, impossible to determine whether or not this is the case from our study.

Our data suggest that the precise aims of a RACPC (rather than the availability of local resources) should determine the level of provision. Centres wishing to develop a service for triaging patients with acute chest pain to prevent unnecessary hospitalisation of those with atypical symptoms are likely to require a daily clinic if they are to have a significant impact. Others who simply wish to expedite the investigation of patients with stable angina may well find that a weekly clinic will suffice.

\section{Patient outcome}

Though RACPCs intuitively seem a good idea, there is little evidence that they fulfil one of their major objectives, which is to quickly, appropriately, and safely reassure patients who are at very low risk of a coronary event. There are few reports describing the follow up of patients with recent onset chest pain who have attended RACPCs, ${ }^{3-10}$ and none in such a large cohort of patients.

Our RACPCs correctly stratified patients into high, intermediate, and low risk groups. There were no cardiac deaths, myocardial infarctions, or coronary artery bypass operations recorded in eight months of follow up in almost 300 patients deemed to be low risk/non-coronary chest pain. Only $2.4 \%$ of these patients had an admission to hospital, over this time, with chest pain (compared with nearly $12 \%$ in patients with acute or stable coronary disease). This low rate of admission to hospital compares very favourably with readmission rates in patients initially hospitalised with chest pain, ${ }^{11}$ and is consistent with data showing that full assessment of patients, including exercise testing, reduces readmission rates. ${ }^{12}$

\section{Unanswered questions}

Several questions about RACPCs are not adequately addressed by this audit. Firstly, do these clinics encourage an approach to patient assessment that risks missing serious non-cardiac pathology? The number of non-cardiovascular deaths in our study was too small to allow statistically significant differences to be detected between groups. It is not clear whether any of these deaths related to symptoms present at the RACPCs, but none occurred within four months of initial attendance. Most general practitioners refer patients to these clinics in order to clarify whether their symptoms are cardiac in origin. The consultation and clinical assessment at RACPCs is quite focused, and this puts a greater onus on general practitioners to refer appropriately, and to consider further investigation when no cause for symptoms has been discovered.

Secondly there is the question of whether these clinics actually improve the overall efficiency of patient management. They may potentially reduce unnecessary hospitalisation, and perhaps divert some of the workload from hard pressed "traditional" outpatient clinics, ${ }^{9}$ but more work is needed to confirm this. Since one of the principal aims of RACPCs is to encourage referral of more patients with suspected angina it seems inevitable that there will be knock-on effects on other parts of the clinical service. For example, it is likely that more patients will be referred for angiography, and this in turn will probably increase demand for coronary revascularisation. ${ }^{3}$ Since rates for coronary artery bypass surgery in the UK lag behind most other countries, this should be regarded as an appropriate development. Certainly it is entirely in accord with the stated aims of the NSF.

\section{CONCLUSION}

Patients with recent onset chest pain can be investigated at a RACPC without compromising their eventual outcome. Those with non-cardiac symptoms can be confidently and appropriately reassured without the need for exhaustive cardiac investigation. The shorter delay from the time of referral may have important advantages in terms of minimising patients' anxiety, and potentially hastening return to employment. Early, effective treatment can be initiated in patients judged to have ischaemic heart disease, and further investigations such as angiography can be scheduled for those at highest risk.

Our data suggest that the precise aims of a RACPC (rather than the availability of local resources) should determine the level of provision. Centres wishing to develop a service for triaging patients with acute chest pain to prevent unnecessary hospitalisation of patients with atypical symptoms are likely to require a daily clinic if they are to have a significant impact. Others who simply wish to expedite the investigation of patients with stable angina may well find that a weekly clinic will suffice.

\section{ACKNOWLEDGMENTS}

We would like to thank our research nurses Mrs K McLeod and Mrs E McGroarty who carried out the data collection for this audit. We would also like to thank Drs E Connolly and Dr P Soraghan, Staff Grade Cardiologists, who assess the patients referred to the Western Infirmary chest pain clinic. Finally we should also like to express our gratitude to our consultant colleagues Drs J A Kennedy and J D McArthur and Professor H J Dargie and Professor W S Hillis at the Western Infirmary and Dr Tom Fyffe at the Southern General Hospital who supervised the respective chest pain clinics.

The audit was part funded by a grant from Bristol-Myers Squibb Pharmaceuticals Ltd.

\section{Authors' affiliations}

J Byrne, D Murdoch, Department of Cardiology, Southern General Hospital, Glasgow, UK

C Morrison, Greater Glasgow Health Board, Glasgow, UK

J McMurray, Department of Cardiology, Western Infirmary, Glasgow, UK

\section{REFERENCES}

1 Gandhi MM, Lampe FC, Wood DA. Management of angina pectoris in general practice: a questionnaire survey of general practitioners. $\mathrm{Br} J$ Gen Pract 1995:45:11-13.

2 Gandhi MM, Lampe FC, Wood DA. Incidence, clinical characteristics, and short-term prognosis of angina pectoris. Br Heart J 1995;73:193-8.

3 Norell M, Lythall D, Coghlan G, et al. Limited value of the resting electrocardiogram in assessing patients with recent onset chest pain: lessons from a chest pain clinic. Br Heart J 1992;67:53-6.

4 Pope JH, Aufderheide TP, Ruthazer R, et al. Missed diagnoses of acute cardiac ischemia in the emergency department. N Engl J Med 2000;342:1 163-70.

5 Capewell S, McMurray J. "Chest pain-please admit": is there an alternative? A rapid cardiological assessment service may prevent unnecessary admissions. BM 2000;320:951-2.

6 National Service Framework. Chapter 4: stable angina (www.doh.gov.uk/nsf/coronary.htm).

7 Tunstall-Pedoe $\mathbf{H}$, Morrison C, Woodward M, et al. Sex differences in myocardial infarction and coronary deaths in the Scottish MONICA population of Glasgow 1985 to 1991. Presentation, diagnosis, treatment, and 28-day case fatality of 3991 events in men and 1551 events in women. Circulation 1996:93:1981-92.

8 Newby DE, Fox KA, Flint LL, et al. A "same day" direct-access chest pain clinic: improved management and reduced hospitalization. Q J Med 1998;91:333-7.

9 el Gaylani N, Weston CF, Shandall A, et al. Experience of a rapid access acute chest pain clinic. Ir Med J 1997;90:139-40.

10 Davie AP, Caesar D, Caruana L, et al. Outcome from a rapid-assessment chest pain clinic. QJ Med 1998;91:339-43.

11 Herlitz J, Karlson BW, Sjolin M. Re-admissions among patients with acute chest pain who were discharged from the emergency department. Eur J Emerg Med 1996;3:31-5.

12 Karlson BW, Wahrborg P, Sjoland H, et al. Impact of a chest pain clinic on recurrency of symptoms and readmissions among patients early discharged from hospital after acute myocardial infarction was ruled out. Eur J Emerg Med 1998;5:29-35. 